\title{
Factors associated with blood pressure disorders in Afro-descendant children and adolescents
}

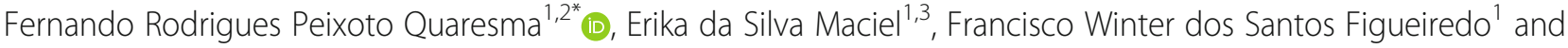 \\ Fernando Adami ${ }^{1}$
}

\begin{abstract}
Background: Hypertension (AH) is an emerging disease that has rapidly increased in the last decades throughout the world. The increase in blood pressure (BP) is observed with growth and development and, although the manifestation of the disease is rare in childhood and adolescence, its occurrence is increasing and the causes are likely to be from different combinations of factors. Afrodescendants have been consistently observed in many populations, including Brazil, which has the largest population of Afrodescendants outside Africa; nevertheless, data is scarce on the disease in children and adolescents. In this study, we investigated BP disorders in children and adolescents of "Quilombola" populations of the state of Tocantins, northern Brazil, and determined the disease occurrence with some factors, namely food consumption, body composition, anthropometric measures, and biochemical data.
\end{abstract}

Methods: We carried out a cross-sectional study with 67 children aged 10-17 years, comparing the variables studied between the normotensive and non-normotensive groups, using the Chi-square test for qualitative variables and the appropriate tests, according to data adherence to the Gaussian distribution for the quantitative variables. High blood pressure was defined as mean systolic or diastolic blood pressure $\geq 90$ percentile for age, height, gender.

Results: The rate of adolescents with BP disorders was 19.4\% (prehypertension 14.9\% and hypertension 4.5\%). There were no significant differences between the sexes for high blood pressure. In the Poisson regression analysis, the high fat percentage was associated with elevated blood pressure $(p=0.021)$ for adolescents. Similar associations were observed for non-HDL-c $(p<0.001)$ and low calcium intake $(p=0.015)$.

Conclusion: Most children and adolescents in "Quilombola" communities had normal blood pressure. However, higher levels of dyslipidemia and low calcium intake are factors associated with prehypertension in the population studied with high BP.

Keywords: Blood pressure, Nutritional status, Physical activity, Anthropometry, Dyslipidemia, Social vulnerability

\section{Background}

The term "quilombo" is associated to a place where communities of black people dwell in Brazil. In their history, black people have faced cruelty, fled from urban areas, and struggled for human rights. In their fight for freedom, they were organized in groups, forming the

\footnotetext{
* Correspondence: ferodriguesto@gmail.com

'Laboratory of Epidemiology and Data Analysis, Faculdade de Medicina do

ABC, Av. Lauro Gomes, 2000, Santo André, São Paulo, Brazil

${ }^{2}$ Federal University of Tocantins, Campus Palmas, Quadra 109 Norte, Avenida

NS15, ALCNO-14 - Plano Diretor Norte, Palmas, TO, Brazil

Full list of author information is available at the end of the article
}

communities of "quilombola" [1]. In 2017, "quilombolas" accounted for roughly 1 million people in Brazil [2], facing numerous difficulties, such as social prejudice and health discrepancies [3, 4].

Most "quilombolas" live in precarious conditions, without basic sanitation and water quality, with limited access to health services, hindering their humanized assistance with quality [5].

In Brazil, 21.4\% of the population shows the systemic arterial hypertension $(\mathrm{SAH})[6]$ disease, and this number is expected to continue to increase in the next years, according

(c) The Author(s). 2019 Open Access This article is distributed under the terms of the Creative Commons Attribution 4.0 International License (http://creativecommons.org/licenses/by/4.0/), which permits unrestricted use, distribution, and reproduction in any medium, provided you give appropriate credit to the original author(s) and the source, provide a link to the Creative Commons license, and indicate if changes were made. The Creative Commons Public Domain Dedication waiver (http://creativecommons.org/publicdomain/zero/1.0/) applies to the data made available in this article, unless otherwise stated. 
to the World Health Organization (WHO) [7]. There is an alert for a higher increase $[8,9]$ among the black population. Brazil has the largest population of Afro-descendants outside Africa $[9,10]$, this requires a priority in the research, prevention and treatment actions.

Other factors for differences in blood pressure disorders in ethnic groups are associated to demographic and socioeconomic components, such as education, income and financial stress that influence the prevalence of $\mathrm{SAH}$ in these populations $[10,11]$.

In children and adolescents, SAH has become frequent and worrisome, as the monitoring of health conditions in children and adolescents is different from that in adults, especially in terms of symptomatology [12].

The prevention of cardiovascular diseases in adulthood $[13,14]$ and risk factors in these groups $[11,15]$ requires the monitoring of blood pressure and people's behaviors.

$\mathrm{SAH}$ is one of the main health problems worldwide; thus, early diagnosis is essential for SAH control and prevention of its secondary injuries. The "quilombola" communities have been affected by health problems of a vulnerable population. Thus, this research investigated the relationship between individual characteristics (gender, age, anthropometry, body composition, blood pressure, biochemical analysis) and lifestyle (dietary intake of sodium, calcium and physical activity level) in BP disorders in adolescents in communities of "quilombola".

\section{Methods}

\section{Study design}

A cross-sectional study was carried out according to STROBE statement [16]. The variables of exposure were socio-demographic characteristics and lifestyle, and BP disorders in "quilombola" adolescents were the outcome variable.

\section{Setting}

The study was carried out in a "quilombola" community in the state of Tocantins, northern Brazil, from June 2015 until November 2016.

The data were collected at facilities of the communities (schools, health units and "quilombola" association place), with the structure (rooms for examinations and interviews) adequately adapted for the research. The interviewers were previously trained and senior researchers with experience in studies on vulnerable communities accompanied the collections.

Data from the Information System on Remnant Communities of "Quilombo" register in Brazil, in 2017, about 2,394 "quilombola" communities. The state of Tocantins has 37 recognized "quilombola" communities and holds the 6th place regarding the number of "quilombola" communities [17].

\section{Participants}

"Quilombola" adolescents, living in five "quilombolas" communities in the state of Tocantins, Brazil. The communities have 121 adolescents from 10 to 17 years old. Of this total, approximately 12 reside in the "Córrego Fundo community"; 18 in "Manoel João"; 28 in "Malhadinha", (municipality of "Brejinho de Nazaré"); 39 in "Barra da Aroeira" (municipality of "Santa Teresa") and 24 in "Morro de São João" (municipality of "Santa Rosa").

The study included all adolescents $(n=121)$ between 10 and 17 years of age, who accepted to participate in the study after consent of parents or guardian $(n=73)$ and completed all collection steps $(n=67)$.

\section{Variables}

For the analysis of this study, quantitative variables were considered (Table 1), as follows:

\section{Data sources/ measurement \\ Anthropometrics}

To measure the variables height $(\mathrm{H})$ and weight $(\mathrm{W})$, we used a wall stadiometer Seca $206^{\circ}$ and a digital scale Hethmeter ${ }^{\circ}$, previously calibrated. The Body Mass Index (BMI) was classified for participants in terms of thinness, leanness, eutrophic, overweight, obese and severe obese, calculating the percentiles by age [18].

Table 1 Demographics, anthropometrics, body composition, blood pressure, physical activity levels, nutrient intake and biochemical analysis

\begin{tabular}{ll}
\hline Variables & Features \\
\hline Gender & Male/Female \\
Age & Age in years \\
Anthropometrics & Height $(\mathrm{cm})$ \\
& Weight $(\mathrm{kg})$ \\
Body composition & BMl $\left(\mathrm{kg} / \mathrm{m}^{2}\right)$ \\
& Fat percentage (\%) \\
Blood pressure & Normotension \\
& Pre-hypertension \\
Physical activity (up to 13 years old) & Hypertension \\
Physical activity (>13 years old) & METs (Meatabolic \\
Nutrient intake & Equivalente Task) \\
& METs \\
& Sodium \\
Biochemical analysis & Total lipids \\
& Calcium \\
\hline
\end{tabular}




\section{Body composition}

We used Tetrapolar ${ }^{\circ}$ [19] Electric Bioimpedance, which consists of a method that conducts a low intensity electricity through the body and measures indicators, such as metabolic rate and fat percentage, among others.

The fat percentage was classified for participants as very low up to $6 \%$ for boys and up to $12 \%$ for girls following, respectively, low from 6.01 to $10 \%$ and 12.01 to $15 \%$, ideal from 10.01 to $20 \%$ and 15.01 to $25 \%$, moderately high from 20.01 to $25 \%$ and 25.01 to $30 \%$, high from 25.01 to $31 \%$ and 30.01 to $36 \%$, and very high greater than $31.01 \%$ and greater than $36.01 \%$ [20].

\section{Systemic blood pressure}

We used the protocol of the VII Brazilian Guideline of Hypertension [21] to measure BP. We used a Tycos ${ }^{\circ}$ mercury manometer with three different sizes of clamps (adult, adolescent, child) and a Littman ${ }^{\circ}$ pediatric stethoscope. Systolic blood pressure (SBP) was determined by the appearance of Korotkoff sounds (K1). The fifth sound of Korotkoff (K5) was the definition of diastolic blood pressure (DBP).

BP disorders in children aged 10 to 12 years and adolescents aged 13 to 17 years were defined as SBP or Diastolic blood pressure $(\mathrm{DBP}) \geq 90$ percentile and hypertension was defined as SBP or DBP $\geq 95$ percentile, according to the most recent guideline [22]. The formulas were based on the relationship between systolic BP (SBP) and diastolic $\mathrm{BP}$ (DBP) ages, heights, genders, according to a study that presents better evidence to identify high BP in children and adolescents [23].

\section{Physical activity level}

To assess the Physical Activity Level (PAL), two instruments were used: for the children at 10 to 13 years of age, we used the PAL Assessment Questionnaire and Sedentary Behavior [24], and for the participants above 14 years of age, the International Physical Activity Questionnaire (IPAQ) long version [25] was used.

The following criteria were used to classify PAL for participants 10 to 13 years of age: sedentary, if the total PAL per week was < 600 MET (Metabolic Equivalent); irregularly active, from 600 to $<1,500 \mathrm{MET} /$ week; active, from 1,500 to 2,900 MET/week; and very active, if $>3$, $000 \mathrm{MET} /$ week. Participants over 13 years of age were classified as sedentary if the total PAL per week was < $150 \mathrm{MET}$; irregularly active, from 150 to $630 \mathrm{MET} /$ week; active, from 631 to 3,149 MET/week; and very active, if $>3,150 \mathrm{MET} /$ week [26].

\section{Food consumption}

We used a record of $24 \mathrm{~h}$ that was applied by nutritionists previously trained through face-to-face interviews to quantify nutrient intake. For this study, only the usual consumption of sodium, calcium and lipids was calculated. The estimate was calculated in the Dietwin ${ }^{\bullet}$ software. The classification was performed using Dietary Reference Intakes [27] according to reference values for age and gender of the participant, which defines $1,5 \mathrm{~g} /$ day for daily (d) intake sodium and 1,3 g/day of calcium.

\section{Biochemical blood analyses}

Fasting glycaemia was evaluated by collecting $5 \mathrm{~mL}$ of blood in a tube without anticoagulant by venipuncture after fasting for 8 to $10 \mathrm{~h}$. Non-HDL-c (High-density lipoprotein cholesterol) was calculated after analyzing cholesterol fractions quantified by the colorimetric enzymatic method with a fully automated spectrophotometer reading. The fractions of LDL-c (Low-density lipoprotein) and VLDL-c (Very low-density lipoprotein) were calculated (Friedwald formula) [28].

The non-HDL-c cholesterol fraction was calculated by the difference between total cholesterol and HDL-c. Total cholesterol is the total sum of potentially atherogenic plasma particles such as VLDL-c, IDL-c (Intermediate low-density lipoprotein) and LDL-c. The result of this calculation provides a better risk estimate compared to LDL-c, especially in cases of hypertriglyceridemia associated to diabetes, metabolic syndrome or renal disease [29].

\section{Bias}

To reduce the risk of bias, there was previous training for instrument application, collection of exams, anthropometric and BP assessments, and the same researcher measured BP twice, according to recommendations [21].

To reduce information bias, an electronic form of data collection was created in Epi info $7.2^{\circ}$ to build the databank. All data were validated in duplicate and in case of divergence between the data, a third researcher was consulted.

\section{Study size}

Due to the scarce references about factors associated with hypertension in "quilombola" adolescents, nonprobabilistic sampling was chosen for convenience, a sample composed of 121 adolescents living in the communities during the study.

\section{Quantitative variables}

For the statistical calculations, we used gross data of variables fat percentage, nutrient intake, fasting glucose and non-HDL-cholesterol. For variables nutritional status, blood pressure, physical activity level, we used the classifications according to recommendations for height, gender and age. 


\section{Statistical methods}

After the standard descriptive statistical analysis, we compared the variables studied between the normotensive and non-normotensive groups (composed of individuals with prehypertension and hypertension) using the Chi-square test for qualitative variables and the appropriate tests, according to with data adherence to the Gaussian distribution. The Shapiro-Wilk test was used to analyze the normality of distribution.

The Poisson regression with robust variance was used to estimate the prevalence ratio grossly and in a multivariate way, following the stepwise forward strategy. The level of confidence was $5 \%$. The program used was Stata (StataCorp, USA) 11.0.

\section{Results}

Among 121 adolescents eligible for the inclusion criterion of the five "quilombola" communities, 67 subjects participated. Fifty-four subjects were considered absence losses after three collection attempts (21\%), refusals (19\%) and withdrawal (5\%) in any of the stages. The greatest loss of data available for the analysis occurred with anthropometric data (Fig. 1).

Most subjects were male $(n=34,50.7 \%)$, eutrophic $(n=37 ; 75.5 \%)$ with an average age of 13 years. Sedentary or irregularly active participants prevailed. Table 2 consolidates the main characteristics on demography, lifestyle, biochemical, and body composition. BP disorders were recorded in 19.4\% and pre-hypertension in 14.9\% (ranging from 6.1 to $23.7 \%$ ), while hypertension was found in $4.5 \%$ (ranging from 0.6 to 9.6\%) of adolescents (Table 2).

In the multivariate analyses, the characteristics that influenced BP disorders were the nutrient intake and biochemical data (Table 3). The non-HDL-c cholesterol $(\mathrm{PR}=1.05$, ranging from 1.03 to $1.08, p<0.001)$, calcium intake $(\mathrm{PR}=1.005$, ranging from 1.001 to $1.01, p=0.015$ ) and fat percentage ( $\mathrm{PR}=1.25$, ranging from 1.03 to 1.51 , $p=0.021$ ) were factors that influenced the increase in blood pressure, when they increased (Table 4).

\section{Discussion}

Our findings showed non-HDL-c, cholesterol excess and low consumption of dietary calcium, as the main causes of BP disorders in "quilombola" adolescents.

For the WHO, cardiovascular diseases are the main death cause worldwide and more people die annually from these diseases than from any other cause, and three-quarters of those deaths occur in low- and middle-income countries. Dyslipidemia represents one of the most significant risk factors of cardiovascular disease [30].

The average serum concentration of non-HDL-c among participants in the study sample was $102.0 \mathrm{mg} / \mathrm{dL}$ (55.9 to 148.1) higher in participants with BP disorders.

The results show that adolescents without changes of BP have less concentration of non-HDL-c cholesterol (with an average difference of $-40.3(-71.3$ to -9.4$)$ )

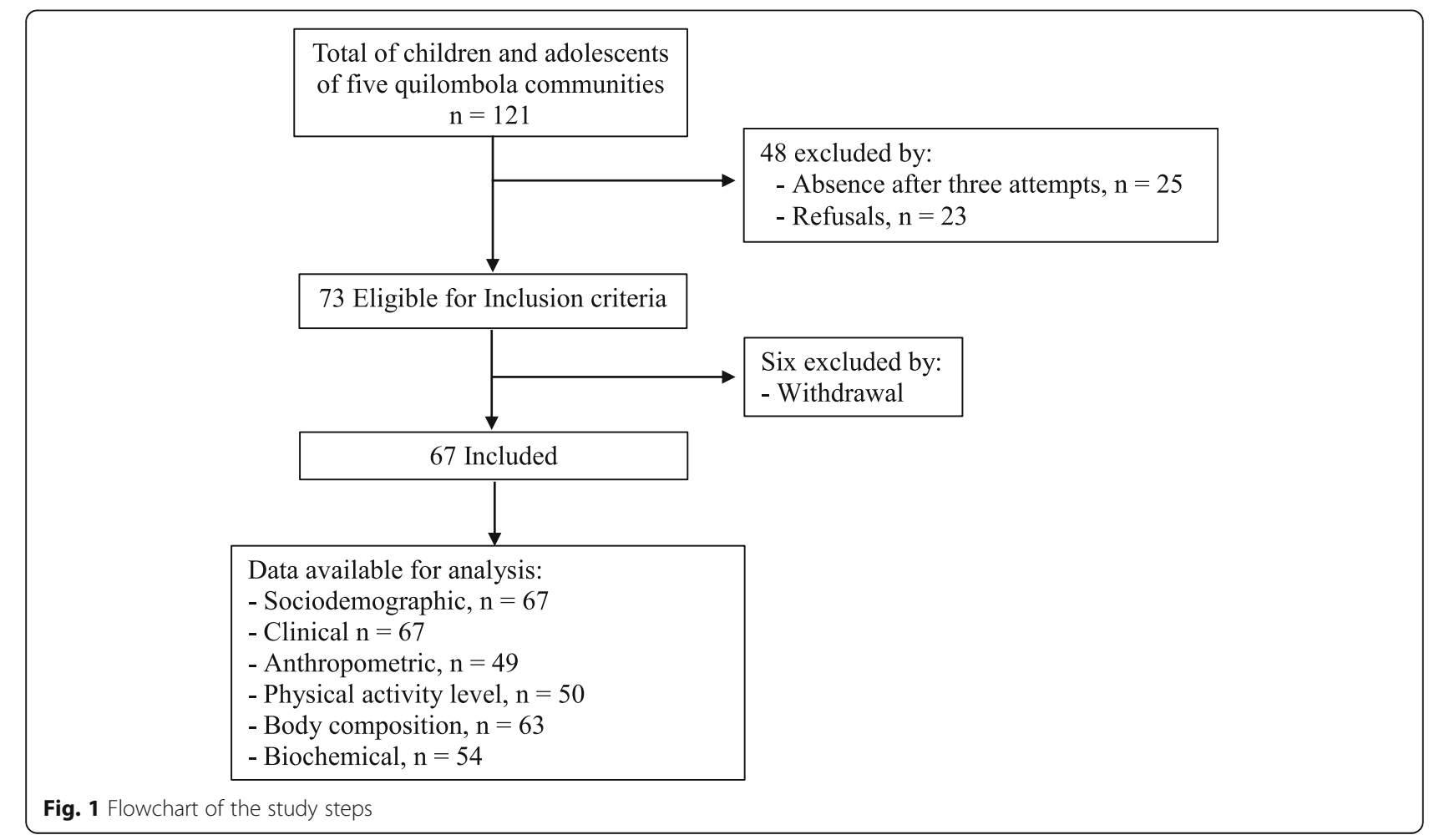


Table 2 Demographic characteristics of "quilombola" adolescents of Tocantins

\begin{tabular}{|c|c|c|}
\hline Features & $\mathrm{N}$ & $\%(\mathrm{Cl} 95 \%)$ \\
\hline \multicolumn{3}{|l|}{ Gender } \\
\hline Female & 33 & $49.3(37.0 ; 61.5)$ \\
\hline Male & 34 & $50.7(38.5 ; 63.0)$ \\
\hline \multicolumn{3}{|l|}{ Nutritional status } \\
\hline Thinness & 6 & $12.2(2.7 ; 21.8)$ \\
\hline Eutrophy & 37 & $75.5(63.0 ; 88.0)$ \\
\hline Overweight & 4 & $8.2(0.2 ; 16.1)$ \\
\hline Obesity & 2 & $4.1(1.6 ; 9.8)$ \\
\hline \multicolumn{3}{|c|}{ Physical activity level (up to 13 years old) } \\
\hline Sedentary & 39 & $100(100.0 ; 100.0)$ \\
\hline Irregularly active & - & - \\
\hline Active & - & - \\
\hline Very active & - & - \\
\hline \multicolumn{3}{|c|}{ Physical activity level (> 13 years old) } \\
\hline Sedentary & - & - \\
\hline Irregularly active & 4 & $36.4(2.4 ; 70.3)$ \\
\hline Active & 7 & $63.6(29.7 ; 97.5)$ \\
\hline Very active & - & - \\
\hline \multicolumn{3}{|l|}{ Blood pressure } \\
\hline Normotension & 54 & $80.6(70.9 ; 90.3)$ \\
\hline Prehypertensive & 10 & $14.9(6.1 ; 23.7)$ \\
\hline Arterial hypertension & 3 & $4.5(0.6 ; 9.6)$ \\
\hline \multirow[t]{2}{*}{ Age } & Mean & $\mathrm{Cl} 95 \%$ \\
\hline & 13.0 & $12.0 ; 14.0$ \\
\hline \multicolumn{3}{|l|}{ Nutrient intake } \\
\hline Sodium ${ }^{a}$ & $2,339.8$ & $1,667.2 ; 2,857.7$ \\
\hline Calcium $^{a}$ & 255.5 & $179.5 ; 302.5$ \\
\hline Biochemical Data & Mean & $\mathrm{Cl}(95 \%)$ \\
\hline Glycaemia $^{\text {b }}$ & 87.5 & $81.0 ; 90.1$ \\
\hline Non-HDL-c Cholesterol ${ }^{\text {b }}$ & 71.8 & $56.3 ; 87.2$ \\
\hline
\end{tabular}

${ }^{a}$ Recommended Dietary Adequate Intakes: sodium $1.00 \mathrm{mg} /$ day, calcium $1,300 \mathrm{mg} /$ day [27]

${ }^{\mathrm{b}}$ Brazilian Guidelines of Dyslipidemia and Atherosclerosis Prevention. Values for teenagers from 10 to 19 years of age: Non HDL-c: < 120 [29]

compared to those with changes in BP. Although we did not find studies that assessed risk factors for BP disorders adolescents taking into account non-HDL-c, the results corroborate with other studies that assessed associations to heart disease using the same variables of this study. Some researchers have pointed out that nonHDL-c is one of the best predictors of atherosclerotic risk in children and adolescents [31, 32] because it is more strongly associated to lesions in the abdominal and coronary aorta than to other lipid fractions [33], in addition to association to metabolic diseases $[34,35]$.
The results for body composition confirm recent findings of Hudson et al. [36] for obese adolescents of 1219 years of age in the United Kingdom, suggesting that $\mathrm{BP}$ disorders were low, despite the positive association of fat percentage with arterial stiffness and adiposity.

Previous evidence [37-40] suggests that adiposity may influence vasculature, leading to hypertension. Other studies also reported that overweight and obesity increased the risk of hypertension 1.22 (95\% CI: 1.05, 1.42) and 1.78 (95\% CI: 1.33, 2.37), respectively [41].

The divergence between the results suggests the need for monitoring these variables during life. In this research, BP disorders in adolescents are associated to obesity and indicates that the social gradient grows toward socially disadvantaged segments, a scenario observed in populations with low economic and schooling levels, corroborating with environmental inequities [42, 43] and health services [44], sine qua nom gears for health promotion and prevention of cardiovascular diseases (CVD).

Studies report that low calcium intakes were inversely related to BP disorders and that increased calcium intake minimizes these risks [45]. Our findings show a significant association between low dietary calcium intake and BP disorders in "quilombola" adolescents with dietary calcium intake lower than $1300 \mathrm{mg}$ /day.

Conversely, Kong et al. [46] assessed the risks of allcause mortality, CVD, Cerebral Vaccine Accident (CVA), or bone fracture due to inadequate dietary calcium, using an epidemiological outline in Korea, with 2153 women and 2158 men. The authors concluded that women with higher calcium intakes were associated to a reduced risk of CVD, but not to stroke or bone fracture, and in men, there was no significant correlation.

There were no significant effects for sodium intake with significant change in BP levels. Both SBP and DBP were slightly higher among BP-free participants who consumed more than $2,300 \mathrm{mg} /$ day of sodium for adolescents who presented changes and consumed less than 2,300 $\mathrm{mg} /$ day $(90 \mathrm{mmHg}$ vs. $110 \mathrm{mmHg}$ for SBP and 60 $\mathrm{mmHg}$ vs. $80 \mathrm{mmHg}$ for DBP, respectively). Similarly, Padilha et al. [47] reported that participants with hypertension showed lower sodium consumption in the diet than those with normal BP. A meta-analysis showed that reductions in dietary sodium lead to modest reductions in children blood pressure [48]. Lower of sodium intake during childhood also appears to protect against increase of blood pressure [49]. Our results may be due to the great variability of using a single 24-h record of dietary data, as well as the lack of temporality. The actual rate of sodium consumption may have been underestimated for the population of this study. In addition, in order to keep healthy BP levels throughout life, there is strong support for initiatives that seek to reduce sodium intake among children [50]. 
Table 3 Association between body features of "quilombola" adolescents, according to systemic arterial hypertension, Tocantins

\begin{tabular}{|c|c|c|c|c|c|}
\hline \multirow[t]{2}{*}{ Features } & \multicolumn{2}{|c|}{ Blood Pressure Classification } & \multirow[t]{2}{*}{$P^{*}$} & \multicolumn{2}{|l|}{ Poisson Regression } \\
\hline & $\begin{array}{l}\text { Normotension }(N=54 \\
80.6 \%)\end{array}$ & $\begin{array}{l}\text { High blood pressure / Hypertension ( } N=13 \text {; } \\
19.4 \%)\end{array}$ & & $\mathrm{RP}(\mathrm{Cl} 95 \%)$ & $p^{* *}$ \\
\hline Gender & n (\%) & & & & \\
\hline Female & $27(81.8)$ & $6(18.2)$ & 0.803 & Ref. & Ref. \\
\hline Male & $27(79.4)$ & $7(20.6)$ & & $1.13(0.38 ; 3.37)$ & 0.823 \\
\hline Nutritional status & $130(12.0 ; 14.0)$ & $12.0(10.0 ; 14.6)$ & 0.382 & $-1.0(-3.7 ; 1.8)$ & 0.471 \\
\hline Eutrophy & $32(86.5)$ & $5(13.5)$ & 0.476 & Ref. & Ref. \\
\hline Overweight / Obesity & $4(66.7)$ & $2(33.3)$ & & $2.46(0.48 ; 12.7)$ & 0.281 \\
\hline \multirow[t]{2}{*}{ Thinness } & $5(83.3)$ & $1(16.7)$ & & $1.23(0.14 ; 10.6)$ & 0.848 \\
\hline & Mean (Cl 95\%) & & $P^{* * *}$ & $\begin{array}{l}\text { Mean Difference (Cl } \\
95 \%)\end{array}$ & $P^{* * * *}$ \\
\hline Age & $13.0(12.0 ; 14.0)$ & $12.0(10.0 ; 14.6)$ & 0.382 & $-1.0(-3.8 ; 1.8)$ & 0.471 \\
\hline \multicolumn{6}{|l|}{ Blood Pressure (mmHg) } \\
\hline Systolic & $90.0(90.0 ; 100.0)$ & $110.0(97.1 ; 120.0)$ & 0.009 & $20.0(-5.2 ; 45.2)$ & 0.118 \\
\hline Diastolic & $60.0(60.0 ; 60.0)$ & $80.0(70.0 ; 80.0)$ & $\begin{array}{l}< \\
0.001\end{array}$ & $20.0(-2.2 ; 42.2)$ & 0.077 \\
\hline \multicolumn{6}{|l|}{ Body composition } \\
\hline Height (in) & $155.4(151.9 ; 158.0)$ & $149.2(135.6 ; 160.9)$ & 0.173 & $-6.2(-14.0 ; 2.5)$ & 0.160 \\
\hline Weight (kg) & $45.0(40.6 ; 47.8)$ & $39.1(29.6 ; 55.2)$ & 0.262 & $-6.4(-16.4 ; 3.6)$ & 0.206 \\
\hline Fat percentage (\%) & $17.6(15.6 ; 21.5)$ & $18.0(10.4 ; 22.8)$ & 0.892 & $0.1(-7.4 ; 7.6)$ & 0.979 \\
\hline \multicolumn{6}{|l|}{ Nutrient intake } \\
\hline Sodium (g) & $2444.1(1337.6 ; 3090.8)$ & $1987.5(862.9 ; 3821.5)$ & 0.819 & $\begin{array}{l}-456.5(-2178.6 ; \\
1265.6)\end{array}$ & 0.597 \\
\hline Calcium (mg) & $220.2(150.9 ; 296.8)$ & 309.9 (192.0; 433.9) & 0.181 & $89.7(-75.3 ; 254.7)$ & 0.281 \\
\hline \multicolumn{6}{|l|}{ Biochemical Data } \\
\hline \multirow[t]{2}{*}{ Glycaemia } & $88.0(81.0 ; 93.0)$ & $85.0(62.4 ; 94.8)$ & 0.333 & $-3.0(-16.8 ; 10.8)$ & 0.663 \\
\hline & Mean (Cl 95\%) & & $p^{*}+$ & Mean Difference & $p^{*}+$ \\
\hline $\begin{array}{l}\text { Non-HDL-c } \\
\text { Cholesterol }\end{array}$ & $60.7(47.5 ; 75.8)$ & $102.0(55.9 ; 148.1)$ & 0.013 & $-40.3(-71.3 ;-9.4)$ & 0.013 \\
\hline
\end{tabular}

Ref Category of reference, Cl 95\% Confidence interval at 95\%; ${ }^{*}$ Chi-square; ${ }^{* *}$ Mann-Whitney Test; ${ }^{* * *}$ Mann-Whitney; ${ }^{* * * *}$ Interquartile Regression; $p^{*}+=$ Student t test

Table 4 Factors associated to blood pressure disorders in male "quilombola" adolescents through the Poisson regression, Tocantins

\begin{tabular}{lll}
\hline Features & \multicolumn{2}{l}{ Poisson Regression } \\
\cline { 2 - 3 } & $\beta(\mathrm{Cl} 95 \%)$ & $p$ \\
\hline Non-HDL-c Cholesterol & $1.05(1.03 ; 1.08)$ & $<0.001$ \\
Calcium & $1.005(1.0001 ; 1.01)$ & 0.015 \\
Weight & $1.07(0.97 ; 1.18)$ & 0.195 \\
Male Gender vs Female Gender ${ }^{\mathrm{a}}$ & $3.39(0.20 ; 56.8)$ & 0.395 \\
Age & $0.83(0.57 ; 1.23)$ & 0.363 \\
Fat percentage & $1.25(1.03 ; 1.51)$ & 0.021 \\
\hline
\end{tabular}

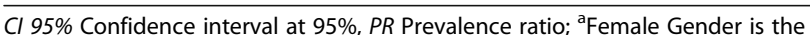
reference category
The findings of this study are subject to some limitations. First, several attempts to collect data from all adolescents in the communities were performed, however, there were data losses that reduced the sample size. Furthermore, the lack of temporality among the variables in a cross-sectional study was an important limitation to the study. This reduced sample size may have been a limitation, given the extrapolation ability of the results found in this study. However, no previous study attempted to assess BP disorders in adolescents of these "quilombola" communities, which makes this study an important parameter to estimate the sample size adequate for other studies.

\section{Conclusion}

The results of this study suggest that the early deregulation of nutrient intake and excess of non-HDL-c cholesterol can 
represent important risk factors of prehypertension in the "quilombola" population. The results indicate the importance of a favorable combination between physical activity and nutrition environments in places where children and adolescents live to sustain a healthy course and behaviors regarding $\mathrm{BP}$ disorders.

\begin{abstract}
Abbreviations
BMI: Body Mass Index; BP: Blood pressure; Cl: Confidence interval; CVA: Cerebral Vaccine Accident; CVD: Prevention of cardiovascular diseases; DBP: Diastolic blood pressure; IPAQ: International Physical Activity Questionnaire; LDL-c: Low-density lipoprotein; MET: Metabolic Equivalent; N: Number; Non-HDL-c: High-density lipoprotein cholesterol; PAL: Physical activity level; RP: Prevalence ratio; SAH: Systemic arterial hypertension: SBP: Systolic blood pressure; STROBE: Strengthening the Reporting of Observational Studies in Epidemiology; VLDL-c: Very low-density lipoprotein; WHO: World Health Organization
\end{abstract}

\section{Acknowledgements}

We thank the "quilombola" communities for their trust, support and participation in this project.

\section{Authors' contributions}

FRPQ contributed to the conception and design of the study, to data acquisition, the analysis and interpretation of the results, and drafting the manuscript. FWSF contributed to the study design, analysis, and interpretation of results. ESM and FA contributed to study conception, study design, and interpretation of results. All authors were involved in writing and revising the manuscript, gave the final approval of the version to be published, and agreed to be accountable for all aspects of the work in ensuring that questions related to the accuracy or integrity of any part of the work be properly investigated and resolved.

\section{Funding}

This research was funded by Program for the Single Health System PPSUS/ TO FAPT-TO/SESAU-TO/MS-DECIT/CNPq (Process No. 01/2014) and Foundation for Research Support of the State of São Paulo in the modality Fomento Regular Program FAPESP (Process No. 2015 / 02549-5). The funders had no role in the design of the study; in the collection, analyses, or interpretation of data; in the writing of the manuscript, or in the decision to publish the results.

\section{Availability of data and materials}

The datasets used and/or analyzed during the current study are available from the corresponding author on reasonable request.

\section{Ethics approval and consent to participate}

This study obtained approval from community leaders and was approved by Ethics Committee of Center University Lutheran of Palmas (Reg. N ${ }^{\circ}$ 56954116.2.0000.5516). As per the permission of the ethics committee, informed verbal consent to participate was obtained from all mothers/ caregivers. During the data collection, the data collectors explained the purpose of the study in Portuguese (local language) and read to them an informed consent script which was approved by the ethics committee. Participants were also assured of confidentiality and anonymity of the information obtained. All participants were informed about the study program and the long-term use of data.

\section{Consent for publication}

Not applicable.

\section{Competing interests}

The authors declare that they have no competing interests.

\section{Author details}

'Laboratory of Epidemiology and Data Analysis, Faculdade de Medicina do ABC, Av. Lauro Gomes, 2000, Santo André, São Paulo, Brazil. ${ }^{2}$ Federal University of Tocantins, Campus Palmas, Quadra 109 Norte, Avenida NS15, ALCNO-14 - Plano Diretor Norte, Palmas, TO, Brazil. ${ }^{3}$ Federal University of
Tocantins, Miracema Campus, Av. Lourdes Solino, 195 - St. Sussuapara, Miracema do Tocantins, TO, Brazil.

Received: 1 November 2018 Accepted: 12 July 2019

Published online: 20 July 2019

\section{References}

1. da Silva PS. Quilombos do Sul do Brasil: movimento social emergente na sociedade contemporânea. Rev Identidade. 2010;15:51-64.

2. Brasil. Secretaria de Políticas para Comunidades Tradicionais. Guia de Políticas Públicas para Comunidades Quilombolas. (2013).

3. Ribeiro GGBL, et al. Who were the male founders of rural Brazilian Afroderived communities? A proposal based on three populations. Ann Hum Biol. 2011;38:237-40

4. Silva JAN d. Condições sanitárias e de saúde em Caiana dos Crioulos, uma comunidade Quilombola do Estado da Paraíba. Saúde Soc. 2007;16:111-24.

5. Freitas DA, Caballero AD, Marques AS, Hernández CIV, Antunes SLNO. Saúde e comunidades quilombolas: uma revisão da literatura. Rev CEFAC. 2011;13:937-43.

6. Andrade SS d A, et al. Prevalência de hipertensão arterial autorreferida na população brasileira: análise da Pesquisa Nacional de Saúde, 2013. Epidemiol Serv Saúde. 2015;24:297-304.

7. WHO. World health statistics 2018: monitoring health for the SDGs: WHO; 2018 http://www.who.int/gho/publications/world_health_statistics/2018/en/.

8. Akinlua JT, Meakin R, Freemantle N. Beliefs about hypertension among Nigerian immigrants to the United Kingdom: a qualitative study. PLoS One. 2017:12:e0181909.

9. Chor D, et al. Prevalence, awareness, treatment and influence of socioeconomic variables on control of high blood pressure: results of the ELSA-Brasil study. PLoS One. 2015;10(6):e0127382.

10. Faerstein $E$, et al. Race and perceived racism, education, and hypertension among Brazilian civil servants: the Pró-Saúde study. Rev Bras Epidemiol. 2014;17:81-7.

11. Carnethon MR, et al. Cardiovascular health in African Americans: a scientific statement from the American Heart Association. Circulation. 2017;136(21): e393-423.

12. Lurbe $E$, et al. 2016 European society ofHypertension guidelines for themanagement of high blood pressure in children and adolescents. J Hypertens. 2016;34(10):1887-920.

13. Ferreira De Moraes AC, Lacerda MB, Moreno LA, Horta BL, Carvalho HB, Prevalence of high blood pressure in 122,053 adolescents: a systematic review and meta-regression. https://doi.org/10.1097/MD.0000000000000232.

14. Rao G. Diagnosis, epidemiology, and management of hypertension in children. Pediatrics. 2016;138. https://doi.org/10.1542/peds.2015-3616.

15. Gonçalves VSS, et al. Prevalência de hipertensão arterial entre adolescentes: revisão sistemática e metanálise. Rev Saude Publica. 2016:50:1-12.

16. von Elm E, et al. The strengthening the reporting of observational studies in epidemiology (STROBE) statement: guidelines for reporting observational studies. PLoS Med. 2007:4:e296.

17. Teixeira TG, Sampaio CAM. Análise orçamentária do Programa Brasil Quilombola no Brasil e no Maranhão: o ocaso de uma política pública. Revista de Administração Pública. 2019;53(2):461-480. Epub April 25. https:// doi.org/10.1590/0034-761220170323.

18. Damé PKV, et al. Sistema de Vigilância Alimentar e Nutricional (SISVAN) em crianças do Rio Grande do Sul, Brasil: cobertura, estado nutricional e confiabilidade dos dados. Cad Saude Publica. 2011;27:2155-65.

19. Biodynamics. Monitor de bioimpedância: manual de instrução. TBW (TBW Importadora). 1999.

20. Lohman TG. The use of skinfold to estimate body fatness on children and youth. J Phys Educ Recreat Dance. 1987;58:98-103.

21. Malachias MVB, et al. $7^{\mathrm{a}}$ Diretriz brasileira de hipertensão arterial. Arq Bras Cardiol. 2016;107:1-103.

22. Flynn $\pi$, et al. Clinical practice guideline for screening and management of high blood pressure in children and adolescents. Pediatrics. 2017;140:e20171904.

23. Mourato FA, et al. New modifications of the blood pressure-to-height ratio for the diagnosis of high blood pressure in children. J Clin Hypertens. 2018; 20:413-5.

24. Militão AG, et al. Reprodutibilidade e validade de um questionário de avaliação do nível de atividade física e comportamento sedentário de escolares de 10 a 13 anos de idade, Distrito Federal, Brasil, 2012. Epidemiol Serv Saúde. 2013;22:111-20. 
25. Matsudo S, et al. International physical activity questionnaire (Ipaq): validity and reproducibility study in Brazil. Rev Bras Atividade Física Saúde. 2012;6:5-18.

26. Ipaq. Guidelines for data processing and analysis of the International Physical Activity Questionnaire (IPAQ). Med Sci Sport Exerc. 2004;35:1-7.

27. Intakes, D. Intakes DR. Dietary Reference Intakes (DRIs): recommended dietary allowances and adequate intakes, vitamins food and nutrition board, institute of medicine, national academies. Food Nutr Board. 2011;10:12.

28. Xavier HT, et al. V Brazilian guidelines on dyslipidemias and prevention of atherosclerosis. Arq Bras Cardiol. 2013;101:01-22.

29. Expert Panel on Integrated Guidelines for Cardiovascular Health and Risk Reduction in Children and Adolescents, E. P. O. I. G. F. C. H. A. R. R. I. C. A. \& National Heart, Lung, and Blood Institute. Expert panel on integrated guidelines for cardiovascular health and risk reduction in children and adolescents: summary report. Pediatrics. 2011;128(Suppl 5):S213-56.

30. Mendis $\mathrm{S}$, et al. Global atlas on cardiovascular disease prevention and control: World Health Organization in collaboration with the World Heart Federation and the World Stroke Organization; 2011. https://www.who.int/ cardiovascular_diseases/publications/atlas_cvd/en/.

31. Nielsen TRH, et al. Childhood obesity treatment; effects on BMI SDS, body composition, and fasting plasma lipid concentrations. PLoS One. 2018;13: e0190576.

32. Riwanto $\mathrm{M}$, et al. Altered activation of endothelial anti- and proapoptotic pathways by high-density lipoprotein from patients with coronary artery disease: role of high-density lipoprotein-proteome remodeling. Circulation. 2013;127:891-904.

33. Lartey A, Marquis GS, Aryeetey R, Nti H. Lipid profile and dyslipidemia among school-age children in urban Ghana. BMC Public Health. 2018;18:320.

34. Ju S-Y, Lee J-Y, Kim D-H. Association of metabolic syndrome and its components with all-cause and cardiovascular mortality in the elderly: a metaanalysis of prospective cohort studies. Medicine (Baltimore). 2017;96:e8491.

35. Mulè G, Calcaterra I, Nardi E, Cerasola G, Cottone S. Metabolic syndrome in hypertensive patients: an unholy alliance. World J Cardiol. 2014;6:890-907.

36. Hudson L, et al. Is arterial stiffening associated with adiposity, severity of obesity and other contemporary cardiometabolic markers in a community sample of adolescents with obesity in the UK? BMJ Paediatr Open. 2017;1: e000061.

37. Cárdenas-Cárdenas LM, et al. Leisure-time physical activity and cardiometabolic risk among children and adolescents. J Pediatr (Versão em Port). 2015;91:136-42.

38. Donahue RP, et al. Risk factors for prehypertension in the community: a prospective analysis from the Western New York health study. Nutr Metab Cardiovasc Dis. 2014;24:162-7.

39. Kulsum-Mecci N, et al. Effects of obesity and hypertension on pulse wave velocity in children. J Clin Hypertens. 2016;19:221-6.

40. Weisbrod RM, et al. Arterial stiffening precedes systolic hypertension in dietinduced obesity. Hypertens (Dallas, Tex. 1979). 2013;62:1105-10.

41. Tarp J, et al. Does adiposity mediate the relationship between physical activity and biological risk factors in youth?: a cross-sectional study from the International Children's Accelerometry Database (ICAD). Int J Obes. 2018;42:671-8.

42. Bezerra VM, Andrade AC d S, de Medeiros DS, Caiaffa WT. Pre-hypertension in quilombola communities in southwestern Bahia, Brazil. Rep Public Health 2017;33:1-14. http://www.scielo.br/scielo.php?pid=S0102-311X2017001005 006\&script=sci_abstract.

43. Mussi RF d F, et al. Excess weight and associated factors in the middle São Francisco state of Bahia, Brazil. Cien Saude Colet. 2018;23:1193-200.

44. Starfield B. The hidden inequity in health care. Int J Equity Health. 2011;10:15.

45. Chan $\mathrm{Q}$, et al. An update on nutrients and blood pressure. J Atheroscler Thromb. 2016:23:276-89.

46. Kong SH, Kim JH, Hong AR, Cho NH, Shin CS. Dietary calcium intake and risk of cardiovascular disease, stroke, and fracture in a population with low calcium intake. Am J Clin Nutr. 2017;106:27-34.

47. Padilha BM, et al. Association between blood cholesterol and sodium intake in hypertensive women with excess weight. Medicine (Baltimore). 2018;97:e0371.

48. Aburto $\mathrm{NJ}$, et al. Effect of lower sodium intake on health: systematic review and meta-analyses. BMJ. 2013;346:f1326.

49. Buendia JR, Bradlee ML, Daniels SR, Singer MR, Moore LL. Longitudinal effects of dietary sodium and potassium on blood pressure in adolescent girls. JAMA Pediatr. 2015;169:560.
50. Selvarajah V, et al. Novel Mechanism for Buffering Dietary Salt in Humans: Effects of Salt Loading on Skin Sodium, Vascular Endothelial Growth Factor C, and Blood Pressure. (Dallas, Tex. 1979). Hypertens. 2017;70:930-937.

\section{Publisher's Note}

Springer Nature remains neutral with regard to jurisdictional claims in published maps and institutional affiliations.
Ready to submit your research? Choose BMC and benefit from:

- fast, convenient online submission

- thorough peer review by experienced researchers in your field

- rapid publication on acceptance

- support for research data, including large and complex data types

- gold Open Access which fosters wider collaboration and increased citations

- maximum visibility for your research: over $100 \mathrm{M}$ website views per year

At BMC, research is always in progress.

Learn more biomedcentral.com/submissions 